\title{
EFEKTIVITAS INOKULUM FUNGI MIKORIZA ARBUSKULA TERHADAP PERTUMBUHAN SEMAI TANAMAN HUTAN
}

\author{
Luluk Setyaningsih* \\ *Fakultas Kehutanan, Universitas Nusa Bangsa \\ Jl. KH. Sholeh Iskandar Km 4, Tanah Sareal, Bogor \\ Email : luluk.setya@gmail.com
}

\begin{abstract}
\section{Effectiveness of mycorrhizal fungi inoculum Arbuskula Growth of seedling Plain Forest}

Utilization of mycorrhizae in forestry are often constrained in the availability of inoculum mukoriza that not every moment can be obtained in sufficient quantities and in accordance with the type of crop and land acidity. It required effort to make the inoculant that can anticipate the condition. It has been developed inoculant arbuscular mycorrhizal fungi (AMF), that explores from various acidity land from under the stands of forest plants, namely inoculum R2, P2, N2 and C2-containing AMF of the genus Glomus sp. The study was conducted with 5 grams inokulasi AMF inoculum (equivalent to 15-30 spores) on seedling sengon (Paraserianthes falcataria), teak (Tectona grandis) and meranti (Shorea leprosula). Observations were carried out for 9 weeks by measuring the height and diameter growth of each week and dry biomass and shoot-root ratio at the end of observation. The statistical analysis was complete randomized with design 5 treatment of inoculant without comparing among species of forest plants seedlings. Results of variance analysis showed that after 9 weeks of observation, AMF inoculum treatments did not significantly affect height growth ( $p<0: 40)$ and diameter ( $p$ $<0.59)$ of sengon seedlings, but significant effect on diameter growth $(p<0: 09)$ and the growth of teak seedlings higher ( $p<0: 06)$ and total dry weight $(B K T)(p<0.07)$ seedling timber. C2 inoculant was effective to increase seedling height growth sengon up to $5 \%$ and meranti up to $22 \%$. R2 inoculant increased height growth for seedlings of teak and meranti respectively $25 \%$ and $81 \%$; Inokulan P2 increased by $23 \%$ and $81 \%$, while the N2 inoculant increased by $21 \%$ and $53 \%$ of seedling growth of teak and meranti. Inoculant R2, P2 and N2 are recommended to be applied to seedlings of teak, and timber, while for legume crops such as sengon more advisable to use inoculants $\mathrm{C} 2$.
\end{abstract}

Key words : inoculum, Arbuscular Mycorrhizal Fungi, Forest plants seedling

\begin{abstract}
ABSTRAK
Pemanfaatan mikoriza di bidang kehutanan sering terkendala pada ketersediaan inokulum mukoriza yang tidak setiap saat dapat diperoleh dalam jumlah cukup dan yang sesuai dengan jenis tanaman serta keasaman lahan. Untuk itu diperlukan upaya untuk membuat inokulan yang dapat mengantisipasi kondisi tersebut. Telah dikembangkan inokulan fungi mikoriza arbuskula (FMA) hasil eksplorasi dari berbagai keasaman lahan dari bawah tegakan tanaman hutan, yaitu inokulum R2, P2, N2 dan C2 yang mengandung FMA dari genus Glomus sp. Penelitian dilakukan dengan menginokulasikan sebanyak 5 gram inokulum FMA (setara 15-30 spora) tersebut pada semai sengon (Paraserianthes falcataria), jati (Tectona grandis) dan meranti (Shorea leprosula). Pengamatan dilakukan selama 9 minggu dengan mengukur pertumbuhan tinggi dan diameter setiap minggu dan biomasa kering serta rasio pucuk-akar pada akhir pengamatan. Penelitian dirancang secara acak lengkap dengan 5 perlakuan inokulan dengan tanpa membandingkan antar jenis semai tanaman hutan. Hasil analisa sidik ragam menunjukan bahwa setelah 9 minggu pengamatan, perlakuan inokulum FMA tidak berpengaruh nyata terhadap pertumbuhan tinggi $(\mathrm{p}<0.40)$ dan diameter $(\mathrm{p}<0.59)$ semai sengon, namun berpengaruh nyata pada pertumbuhan diameter $(\mathrm{p}<0.09)$ semai jati dan pertumbuhan tinggi $(\mathrm{p}<0.06)$ serta berat kering total $(B K T)(\mathrm{p}<0.07)$ semai meranti . Inokulan $\mathrm{C} 2$ efektif untuk peningkatan pertumbuhan tinggi semai sengon hingga 5\% dan meranti hingga $22 \%$. Inokulan R2 mampu meningkatkan pertumbuhan tinggi semai jati dan meranti masing-masing sebesar $25 \%$ dan 81\%; Inokulan P2 meningkatkan sebesar 23\% dan 81\%; sedangkan inokulan N2 mampu meningkatkan sebesar $21 \%$ dan $53 \%$ terhadap pertumbuhan semai jati dan meranti. Inokulan R2, P2 dan N2 lebih disarankan untuk diaplikasikan pada semai jati, dan meranti, sedangkan untuk tanaman legum seperti sengon lebih disarankan menggunakan inokulan $\mathrm{C} 2$.
\end{abstract}

Kata kunci : Inokulum, Fungi Mikoriza arbuskula, Semai tanaman hutan 


\section{PENDAHULUAN}

Fungi mikoriza arbuskula (FMA) merupakan salah satu fungi yang mampu membentuk simbiosis saling menguntungkan antara cendawan dengan akar tanaman, yang dapat meningkatkan kapasitas dalam menyerap unsur hara dan air (Brundrett et al. 1994), seperti unsur fosfat (Bolan 1991) yang ketersedianya pada tanah-tanah masam dan tanah dengan $\mathrm{pH}$ tinggi, menjadi terbatas, sehingga seringkali menjadi salah satu pembatas utama dalam meningkatkan produktivitas tanaman.

\section{Pemanfaatan mikoriza di bidang} kehutanan untuk meningkatkan pertumbuhan semai tanaman kehutanan semakin luas, terutama pada lahan-lahan marginal yang ditandai dengan tingkat keasaman tinggi. Namun demikian pemanfaatannya dalam jumlah besar masih terkendala dengan tidak tersedianya inokulan mikoriza pada jumlah yang cukup pada saat dibutuhkan. Selain itu, seringkali inokulan yang ada bersifat sangat spesifik sehingga hanya sesuai untuk jenis tanaman tertentu saja dengan range tingkat keasaman media yang juga terbatas. Sehingga inokulan yang ada hanya terbatas penggunaanya. Oleh karenanya diperlukan adanya inokulan yang memiliki kemampuan berasosiasi dengan sebaran jenis tanaman dan kondisi keasaman yang lebih luas.

Penggunaan isolate FMA secara tunggal, Glomus etunicatum, pernah dilaporkan mampu meningkatkan pertumbuhan tinggi semai mindi yang ditanam pada tailing yang diberi kompos hingga $22 \%$. Isolat yang sama juga mampu meningkatkan serapan N, P, K semai mindi (Setyaningsih, 2007). Pengaruh interaksi antara CMA jenis Glomus clarum (KLP-1) dengan dosis bio-organik $15 \%$ menunjukkan pertambahan nilai rata - rata tertinggi sebesar $41,3 \mathrm{~cm}$ atau $190 \%$ dibandingkan dengan kontrol (Pidjath, 2007)

Sementara itu, penggunaan isolate campuran 4 FMA yang tergabung dalam inokulan Mycofer telah dipaorkan pula mampu meningkatkan pertumbuhan tinggi semai sampai $550 \%$ dibandingkan kontrol (tanah podsolik merah kuning tanpa kompos dan tanpa mikoriza) atau sebesar $18 \%$ dibandingkan tanpa inokulan, serta meningkatkan serapan $\mathrm{Pb}$ pada media tailing sebesar $8 \%$ dibandingkan dengan yang tidak diinokulasi (Setyaningsih, 2007).

Penelitian ini ditujukan untuk mengetahui efektivitas inokulan FMA dalam meningkatkan pertumbuhan semai tanaman hutan. Sebanyak 4 inokulan FMA, R2, P2, C2 dan N2, digunakan dalam penelitian ini, merupakan hasil pengembangan dari eksplorasi yang telah dilakukan pada beberapa lokasi dengan keasaman berbeda dan dari bawah beberapa tegakan hutan.

\section{METODOLOGI PENELITIAN}

Sebanyak 2 inokulan FMA, yaitu: R2, P2, C2 dan N2, yang masing-masing mengandung FMA dari genus Glomus. Inokulum tersebut secara beruurut diisolasi dari bawah tegakan Acacia cracicarpa di lahan gambut dengan $\mathrm{pH}$ 3.7-4.8; sengon (Paraserianthes falcataria) di lahan berjenis tanah latosol dengan $\mathrm{pH}$ 5.1-5.9 ; dan dari bawah tegakan Karet (Hevea brasiliencis) di lahan berjenis tanah latosol dengan $\mathrm{pH}$ 4.8-5.8; dan dari bawah tegakan mahoni (Swietenia mahagoni) di lahan berjenis tanah campuran tailing tanah PMK dengan $\mathrm{pH}$ 4.5-5.1 (Setyaningsih et al. 2009) Inokulum tersebut dikembangkan menggunakan zeolit sebagai media pembawanya, dengan kandungan spora FMA berkisar antara 1530 per 5 gram inokulum.

Sebanyak 5 gram inokulum diberikan pada semai tanaman hutan, jati (T. grandis), sengon (Paraserianthes falcataria) dan meranti (Shorea leprosula) umur 1 minggu setelah penyapihan pada media tanah. Jenis tanah dan tingkat keasaman dari masing - masing media tanam semai tersebut secara berurut adalah latosol berkapur dengan $\mathrm{pH}$ 6-7, latosol dengan $\mathrm{pH}$ 5.7-6.3 dan podsolik merah kuning/PMK dengan $\mathrm{pH} 4.3-5.5$.

Tinggi, diameter merupakan variabel pertumbuhan yang diamati setiap 
minggu hingga 9 minggu pengamatan, dan biomasa kering serta rasio pucuk-akar yang diamati pada akhir penelitian. Pertumbuhan tinggi dan diameter merupakan pengurangan atas tinggi/diameter akhir pengamatan dengan tinggi/diameter awal pengukuran. Biomasa kering atau berat kering total (BKT) diperoleh dengan menambahkan berat kering bagian pucuk semai (batang dan daun) dengan bagian akar yang telah dikeringkan dalam oven dengan suhu $70^{\circ} \mathrm{C}$ hingga mencapai berat konstan (lebih kurang 24 jam). Rasio pucuk akar (T/R) adalah perbandingan berat kering pucuk dengan berat kering akar. Penelitian dirancang secara acak lengkap dengan 5 jenis perlakuan inokulasi FMA, yaitu Tanpa inokulasi, Inokulasi R2, Inokulasi $\mathrm{P} 2$, Inokulasi N2, dan Inokulasi C2. Masing-masing jenis semai tanaman hutan tidak saling dibandingkan.

\section{HASIL PENELITIAN}

Setelah 9 minggu pengamatan, hasil analisa sidik ragamnya, sebagaimana pada Tabel 1, menunjukan bahwa perlakuan FMA tidak berpengaruh nyata terhadap pertumbuhan tinggi $(\mathrm{p}<0.40)$ dan diameter $(\mathrm{p}<0.59)$ semai sengon, namun berpengaruh nyata pada pertumbuhan diameter $(\mathrm{p}<0.09)$ semai Jati dan pertumbuhan tinggi $(\mathrm{p}<0.06)$ serta berat kering total $(\mathrm{BKT})(\mathrm{p}<0.07)$ semai Meranti umur 9 minggu. Perbedaan pengaruh antar perlakuan terhadap pertumbuhan dari masing-masing jenis semai diuraikan lebih lanjut dibawah.

\section{Semai Sengon ( $P$. falcataria)}

Hasil uji Duncan, pada Tabel 2, menunjukan bahwa inokulasi FMA pada semai sengon tidak memberikan pengaruh yang berbeda terhadap pertumbuhan tinggi, diameter, berat kering total maupun rasio berat kering pucuk-akar, dengan semai yang tanpa inokulasi FMA (ditunjukan huruf yang sama pada kolom).

Namun demikian inokulan FMA $\mathrm{C} 2$, memiliki kecenderungan memberikan pertumbuhan tinggi, diameter dan BKT yang lebih besar, dengan pertambahan tinggi mencapai $17 \mathrm{~cm}$, diameter $0.16 \mathrm{~cm}$, BKT 8.30 gram. Seluruh semai baik yang diinokulasi FMA maupun yang tanpa FMA mempunyai rasio berat kering pucuk akar yang masih berada pada kisaran normal, 1.7-2.1.

Tabel 1. Hasil Analisa Sidik Ragam Pengaruh FMA terhadap Pertumbuhan Tinggi dan Diameter Semai Tanaman Hutan Umur 9 minggu setelah tanam.

Probabilitas Pengaruh FMA

\begin{tabular}{|c|c|c|c|c|}
\hline $\begin{array}{c}\text { Semai Tanaman } \\
\text { Hutan }\end{array}$ & $\begin{array}{c}\text { Pertambahan } \\
\text { tinggi }\end{array}$ & $\begin{array}{c}\text { Pertambahan } \\
\text { diameter }\end{array}$ & $\begin{array}{l}\text { Berat Kering } \\
\text { Total (BKT) } \\
\end{array}$ & $\begin{array}{c}\text { Rasio BK } \\
\text { Pucuk-Akar }\end{array}$ \\
\hline Sengon ( $P$. falcataria) & $<0.40^{\mathrm{ns}}$ & $<0.59^{\mathrm{ns}}$ & $<0.43^{\mathrm{ns}}$ & $<0.95^{\mathrm{ns}}$ \\
\hline Jati (T. grandis) & $<0.71^{\mathrm{ns}}$ & $<0.09 *$ & $<0.79^{\text {ns }}$ & $<0.34^{\mathrm{ns}}$ \\
\hline Meranti (S. leprosula) & $<0.060 *$ & $<0.93^{\mathrm{ns}}$ & $<0.07^{*}$ & $<0.81^{\mathrm{ns}}$ \\
\hline
\end{tabular}

Keterangan: * Perlakuan berpengaruh nyata pada tingkat kesalahan uji 5\%

ns Perlakuan berpengaruh tidakk nyata ada tingkat kkesalahan uji 5\% 


\section{Semai Jati (T.grandis)}

Hasil uji Duncan menunjukan bahwa inokulasi FMA pada semai jati umur 9 minggu memberikan pengaruh nyata hanya terhadap pertumbuhan diameter. Pertumbuhan tinggi dan diameter semai yang diinokulasi C2 cenderung lebih kecil dari semai lainnya, bahkan dengan semai yang tidak diinokulasi sekalipun. Sedangkan pertumbuhan tinggi dan diameter ditunjukan oleh semai yang diinokulasi N2, yaitu $4.95 \mathrm{~cm}$ dan $0.36 \mathrm{~cm}$ hingga umur 9 minggu, walaupun BKT nya belum yang terbesar (11.35 gram). Nilai rasio berat kering pucuk-akar semai jati yang diinokulasi maupun yang tidak diinokulasi FMA tidak berbeda nyata dan berada pada kisaran dibawah 1 (atau 0.5 $0.7)$.

\section{Semai Meranti (S. leprosula)}

Hasil uji Duncan menunjukan bahwa inokulasi FMA pada semai meranti umur 9 minggu memberikan pengaruh nyata terhadap pertumbuhan tinggi dan BKT. Pengaruh terbaik terhadap pertumbuhan tinggi diberikan oleh inokulan R2 $(8.7 \mathrm{~cm})$ dan P2 $(8.6 \mathrm{~cm})$; sedangkan BKT tertinggi ditunjukan oleh semai yang diinokulasi N2 (5.14 g). Semai meranti yang tidak diinokulasi FMA memiliki pertumbuhan tinggi terkecil (4.9 $\mathrm{cm}$ ), dengan pertumbuhan diameter yang tidak berbeda nyata dengan lainnya.

Rasio berat kering pucuk-akar semai meranti baik yang diberi inokulan FMA maupun yang tanpa inokulan FMA tidak berbeda nyata dan berada pada kisaran antara $1.2-1.7$.

Tabel 2. Pengaruh Inokulasi FMA terhadap Pertumbuhan Semai Sengon Umur 9 minggu berdasarkan Hasil Uji DMRT

\begin{tabular}{|c|c|c|c|c|c|c|c|c|}
\hline \multirow{3}{*}{$\begin{array}{c}\begin{array}{c}\text { Inoluan } \\
\text { FMA }\end{array} \\
\text { Tanpa }\end{array}$} & \multicolumn{6}{|c|}{ Pertumbuhan } & \multirow{2}{*}{\multicolumn{2}{|c|}{$\begin{array}{c}\text { Rasio BK } \\
\text { Pucuk-Akar }\end{array}$}} \\
\hline & \multicolumn{2}{|c|}{ Tinggi (cm) } & \multicolumn{2}{|c|}{ Diameter (cm) } & \multicolumn{2}{|c|}{ BKT (gram) } & & \\
\hline & 16.52 & $\mathrm{a}$ & 0.15 & $a$ & 7.97 & $\mathrm{a}$ & 1.7 & $\mathrm{a}$ \\
\hline R2 & 13.50 & $\mathrm{a}$ & 0.12 & $\mathrm{a}$ & 8.27 & $\mathrm{a}$ & 1.7 & $\mathrm{a}$ \\
\hline $\mathrm{P} 2$ & 12.40 & $\mathrm{a}$ & 0.14 & $\mathrm{a}$ & 5.83 & $\mathrm{a}$ & 2.0 & $\mathrm{a}$ \\
\hline $\mathrm{C} 2$ & 17.00 & $\mathrm{a}$ & 0.16 & $\mathrm{a}$ & 8.30 & $\mathrm{a}$ & 2.0 & $\mathrm{a}$ \\
\hline $\mathrm{N} 2$ & 11.48 & $\mathrm{a}$ & 0.11 & $\mathrm{a}$ & 7.90 & $\mathrm{a}$ & 2.1 & $\mathrm{a}$ \\
\hline
\end{tabular}

Keterangan : Angka pada kolom yang diikuti oleh huruf yang sama menunjukan tidak terdapat perbedaan nyata pada tingkat kesalahan uji 5\% dalam pengujian DMRT

Tabel 3. Pengaruh Inokulasi FMA terhadap Pertumbuhan Semai Jati Umur 9 minggu berdasarkan Hasil Uji DMRT

\begin{tabular}{|c|c|c|c|c|}
\hline \multirow[b]{2}{*}{$\begin{array}{c}\text { Inoluan } \\
\text { FMA }\end{array}$} & \multicolumn{3}{|c|}{ Pertumbuhan } & \multirow[b]{2}{*}{$\begin{array}{c}\text { Rasio BK } \\
\text { Pucuk-Akar }\end{array}$} \\
\hline & Tinggi (cm) & Diameter (cm) & BKT (gram) & \\
\hline Tanpa & 3.92 & $0.36 \mathrm{~b}$ & $9.39 \mathrm{a}$ & $0.5 \quad \mathrm{a}$ \\
\hline $\mathrm{R} 2$ & $4.55 \mathrm{a}$ & $0.29 \mathrm{ab}$ & 13.09 & 0.5 \\
\hline $\mathrm{P} 2$ & $4.87 \quad \mathrm{a}$ & $0.32 \mathrm{ab}$ & 14.62 & 0.5 \\
\hline $\mathrm{C} 2$ & $3.57 \mathrm{a}$ & $0.24 \quad \mathrm{a}$ & 11.35 & 0.5 \\
\hline $\mathrm{N} 2$ & $4.95 \mathrm{a}$ & $0.36 \quad \mathrm{~b}$ & 11.49 & 0.7 \\
\hline
\end{tabular}

Keterangan : Angka pada kolom yang diikuti oleh huruf yang sama menunjukan tidak terdapat perbedaan nyata pada tingkat kesalahan uji 5\% dalam pengujian DMRT 
Tabel 4. Pengaruh Iinokulasi FMA terhadap Pertumbuhan Semai Meranti Umur 9 minggu berdasarkan Hasil Uji DMRT

\begin{tabular}{|c|c|c|c|c|}
\hline \multirow[b]{2}{*}{$\begin{array}{c}\text { Inoluan } \\
\text { FMA }\end{array}$} & \multicolumn{4}{|c|}{ Pertumbuhan } \\
\hline & Tinggi $(\mathbf{c m})$ & Diameter (cm) & BKT (gram) & $\begin{array}{c}\text { Rasio BK } \\
\text { Pucuk-Akar }\end{array}$ \\
\hline Tanpa & 4.9 & 0.13 & 4.16 & 1.3 \\
\hline $\mathrm{R} 2$ & 8.7 & 0.14 & $4.43 \mathrm{ab}$ & 1.7 \\
\hline $\mathrm{P} 2$ & $8.6 \mathrm{~b}$ & $0.12 \mathrm{a}$ & 4.58 & 1.6 \\
\hline $\mathrm{C} 2$ & $5.7 \quad a b$ & 0.12 & 3.47 & 1.6 \\
\hline $\mathrm{N} 2$ & $6.9 \mathrm{ab}$ & 0.14 & 5.14 & 1.2 \\
\hline
\end{tabular}

Keterangan : Angka pada kolom yang diikuti oleh huruf yang sama menunjukan tidak terdapat perbedaan nyata pada tingkat kesalahan uji 5\% dalam pengujian DMRT

\section{PEMBAHASAN}

Hasil uji efektifiktas inokulan hasil eksplorasi diketahui bahwa masing masing inokulan (R2, P2, N2 dan $\mathrm{C} 2$ ) memberikan pengaruh yang berbeda terhadap pertumbuhan semai hutan dari jenis yang berbeda. Inokulan C2 terindikasi dapat meningkatkan pertumbuhan tinggi semai Sengon hingga $5 \%$ dan Meranti hingga 22\%, tetapi tidak meningkatkan pertumbuhan tinggi semai Jati. Inokulan R2 mampu meningkatkan pertumbuhan tinggi semai Jati dan Meranti masing - masing sebesar 25\% dan 81\%; Inokulan P2 meningkatkan sebesar 23\% dan $81 \%$; sedangkan inokulan N2 mampu meningkatkan sebesar $21 \%$ dan $53 \%$ terhadap pertumbuhan semai jati dan meranti. Fenomena pengaruh yang berbeda ini juga ditemukan pada hasil penelitian sebelumnya, seperti pada semai balsa, terjadi efisiensi pertambahan tinggi sebesar $60 \%$ pada semai yang diinokulasi Glomus sp (M1), dan $21 \%$ pada semai yang diinokulasi Acaulospora sp (M2). Sedangkan pada semai mahoni, terjadi efisiensi pertambahan tinggi sebesar $94 \%$ pada semai yang diinokulasi Glomus sp (M1), dan $64 \%$ pada semai yang diinokulasi Acaulospora sp (M2) (Setyaningsih et al. 2009).

Peningkatan pertumbuhan tinggi oleh FMA tidak selalu diikuti dengan peningkatan pertumbuhan diameter semai; hanya inokulan $\mathrm{C} 2$ yang cenderung memberikan peningkatan pertumbuhan diameter pada semai sengon dan meranti; sedangkan inokulan lainnya cenderung sama atau mengurangi pertumbuhan diameter semai, walau pengurangannya tidak lebih dari 5\%. Variabel pertumbuhan semai lainnya, BKT, cenderung meningkat dengan inokulasi FMA, dengan peningkatan $5-55 \%$ pada semai sengon, meranti dan jati.

Kondisi tersebut memberikan gambaran bahwa inokulan FMA memiliki kemampuan yang spesifik. Spesifik terhadap jenis semai tanaman hutan, dan spesifik terhadap bagian dari tanaman yang terstimulasi pertumbuhannya. Terjadinya peningkatan pertumbuhan tinggi yang lebih besar dengan inokulasi FMA dibandingkan dengan pertumbuhan diameter, diduga didorong oleh kharakter fisiologi tanaman hutan yang cenderung melakukan pertumbuhan primer (tinggi) pada awal pertumbuhannya.

Informasi ini sekaligus dapat dijadikan sebagai indikator untuk menentukan kesesuaian inkulan FMA dengan jenis semai yang akan ditanam, juga untuk menyesuaikan dengan tujuan pertumbuhan tanaman yang ingin dicapai.

Walaupun setiap inokulan FMA memiliki kecenderungan kesesuaian yang spesifik dengan jenis semai tanaman hutan, 
namun keempat inokulan yang diaplikasikan, seluruhnya dapat meningkatkan pertumbuhan tinggi semai meranti hingga $81 \%$ dan juga BKT nya hingga 5\%. Fenomena ini menunjukan bahwa meranti memiliki ketergantungan yang tinggi terhadap kolonisasi FMA. Ketergantungan tersebut sangat mungkin didorong oleh kondisi media semai meranti yang cenderung masam $(4.5 \leq \mathrm{pH}<5.5)$ yang menyebabkan ketersediaan hara makro P rendah, sebagai akibat terfiksasinya unsur tersebut oleh $\mathrm{Al}$ atau Fe (Smith and Read 1997). Kolonisasi FMA dengan akar semai akan terstimulasi untuk bekerja dalam kondisi ekstrim tersebut, melalui pelepasan enzim fosfatase dalam rangka memecahkan ikatan $\mathrm{Al}$ dan Fe terhadap $\mathrm{P}$, hingga terjadi peningkatan ketersediaan fosfat. Hasil penelitian ini senada dengan hasil - hasil penelitian pemanfaatan FMA pada beberapa jenis tanaman lainnya, seperti peningkatan tinggi mencapi $20 \%$ lebih tinggi pada semai sawit yang ditanam pada tanah asam podsolik merah kunging (Kartika, 2006). Dengan demikian aplikasi inokulan FMA terhadap semai meranti menjadi penting untuk selalu dilakukan, selain karena secara genetik sifat tanamanya yang memiliki ketegantungan terhadap keberadaan mikoriza, juga karena meranti lebih menyenangi tumbuh pada lahan masam, yang cenderung mengalami defisiensi unsur fosfor yang berkonseskuesi membutuhkan mikoriza untuk membantu menyediakannya.

Inokulan R2, P2 dan N2 lebih disarankan untuk diaplikasikan pada semai Jati, dan Meranti; sedangkan untuk tanaman legum seperti sengon lebih disarankan menggunakan inokulan $\mathrm{C} 2$.

\section{UCAPAN TERIMAKASIH}

Terimakasih yang sebesar besarnya disampaikan kepada Direktorat Jenderal Pendidikan Tinggi, Kementerian Pendidikan Nasional, yang telah membiayai penelitian ini berdasarkan Surat Perjanjian Pelaksanaan Hibah Penelitian Nomor : 206/SP2H/PP/DP2M/III/2010 Tanggal 01 Maret 2010.

\section{DAFTAR PUSTAKA}

Allen, M. F. dan Allen, E. B. 1992. Development of Mycorrhizal Patches in a Successional Arid Ecosystem. Pp 164-170. In : Mycorrhizas in Ecosystem. (Eds. Read, D. j., Lewis, D. L., Fitter, A. H., and Alexander, L. J.). CAB International. Wallingford, UK.

Alloway, B. J. 1995. Heavy Metals in Soil. 2nd Edition. Blackie Academic and Profesional. London.

Allen, EB, Cunningham GL. 1983. Effect of vesicular-arbuscular mycorrhizae on Distichlis spicata under three salinity levels. New Phytol. 93:227-236

Brundrett, M., Bougher N., Dell B., Grove T., and Maljczuk N. 1996. Working With Mycorrhizas in Forestry and Agriculture. ACIAR Monograph Series. Canbera

Clark RB. 1997. Arbuscular mycorrhizal adaptation, spore germination, root colonization, and host plant growth and mineral acquisition at low pH. Plant and Soil 192 : 1522

Ekamawanti HA, Rukmi I, Rahayu S. $1994 . \quad$ Eksplorasi keanekaragaman cendawan mikoriza arbuskular (CMA) pada lahan gambut. Makalah dalam seminar on Self Development Project. Universitas Andalas. Padang (tidak dipublikasikan)

Evayenri. 1998. Studi Keanekaragaman dan potensi inokulum cendawan mikoriza arbuskula (CMA) di lahan gambut (studi kasus di Kabupaten Bengkalis Prop. Riau). Thesis. Program Pasca Sarjana IPB, Bogor. 
Gerdemann, J. W. 1968. VasicularArbuscular Mycorrhizae and Plant Growth. Annual Review of Phytopathology 6 : 397-418

Harmet, T. Habazar, E. Husin, dan D. P. Putra. 2000. Peranan Cendawan Mikoriza Arbuskula dan Pupuk fosfor dalam peningkatan Ketahanan Tanaman Kedelai terhadap Penyakit Pustul Bakteri (Xanthomonas campestris pv glycines). Prosiding Seminar Nasional Mikoriza I.

Kartika, Elis. 2006. Tanggap Pertumbuhan, serapan hara, dan karakter morfologis terhadap cekaman kekeringan bibit kelapa sawit yang bersimbiosis dengan CMA. Sekolah Pasca Sarjana IPB. Disertasi.

Mosse, B. 1981. Vesicular-Arbuscular Mycorrhiza Research for Tropical Agriculture. Research Bulettin 174. Hawai Institute of Tropical Agriculture and Human Resources, University of Hawaii

Muthukumar P. 1999. Vesicular arbuscular Mycorrhizae in Tropical sedges of Southern India. Biol Fertil Soil 22 : 96-100
Phipps CJ, Taylor TN. 1996. Mixed arbuscular mycorrhizae from the Triassic of Antartica. Mycology 88 (5) : 707-714.

Pidjath, C. 2007. Kualitas Bibit Acacia crassicarpa A. Cunn. ex Benth Hasil Sinergi Bi-Organik dengan Cendawan Mikoriza Arbuskula di Ultisol. Institut Pertanian Bogor. Thesis.

Purwanto A. 1999. Studi hubungan salinitas dengan kelimpahan CMA pada lahan hutan pantai dan hutan mangrove di Cagar Alam Leuweung Sancang Kab. Garut Jawa Barat. Jurusan Manajemen Hutan. Fakultas Kehutanan IPB. Skripsi.

Setyaningsih, L. 2007. Pemanfaatan Cendawan Mikoriza Arbuskula dan Kompos Aktif dalam Meningkatkan Pertumbuhan Semai Mindi (Melia azedarach. Linn) pada Media Tailing Tambang Emas Pongkor. Institut Pertanian Bogor. Thesis.

Smith, S.E. and Read, D. J. 1997. Mycorrhizal Symbiosis. Academic Press Limited. London. 